Administrative Issues Journal: Connecting Education, Practice, and Research, Winter 2020, Vol. 10, No. 2: 18 - 32. DOI: 10.5929/2020.10.2.2

\title{
AUTHENTIC ENGAGEMENT THROUGH WORKPLACE PEDAGOGY
}

\section{Chynette Nealy University of Houston Downtown}

\begin{abstract}
Readiness: Are business majors equipped with industry-expected skills? This question remains the central theme of discussions between employers and business academicians in terms of bridging the gap between theory and practice. These discussions are useful in identifying reasons that might impede "readiness." This article provides an overview of pedagogical and practical considerations by offering a process and evaluation framework to help business communication faculty integrate workable pedagogy to ever-evolving business practices. Suggestions are provided for authentically engaging business majors in developing industry-expected skills, such as teamwork, social collaboration, and technology. Although these suggestions will not pertain equally to all business communication settings (i.e. regional or local practices), they do allow for the examination, reflection, and application of best practices to bridge the gaps between theory and practice in terms of providing meaning and value for undergraduate business majors to develop applicable workplace and employability skills. These uncertain times underscore the importance of reflecting on and applying best practices from academic and workplace settings that can authentically engage and develop students.
\end{abstract}

Keywords: authentic engagement, business communication, readiness, theory and practice

Categories: Education, Theoretical Framework, Business Communication

\section{Introduction}

R eadiness: Are business majors equipped with industry-expected skills?

The question of readiness has been assessed, and "for more than 20 years, deficiencies in transferable workplace skills have been a focus of federal workforce initiatives; yet, enacting a plethora of laws, goals and guidelines has not resolved the problems" (McNarama, 2019, p. 25). In an effort to summarize these decades of extant literature, the author suggests review of MacDermott and Ortiz (2017) "historical overview of job readiness from both the employer and graduate standpoint" ( $p$. 1). The authors highlight a question asked of business schools: "Do you give students a set of skills that is going to serve them well over their careers?" (p. 4) This question remains the central theme of discussions between employers and business academicians in terms of bridging the gap between theory and practice. These discussions are useful in identifying reasons that might impede readiness, such as:

"How well are colleges and universities preparing graduates for the workplace? The National Association of Colleges and Employers (NACE) as well as the Association of American Colleges and Universities (AACU) conducts annual employer surveys about new graduate career 
preparation. Along with determining employer needs, other research has looked at the gap between what the workplace demands of new hires and how well colleges and universities are helping students translate their academic accomplishments into workplace success" (MacDermott \& Ortiz, 2017, p.4; Peddle, 2000; Thomas, 2007; David \& David, 2011; Dragoo \& Barrows, 2016; and Tewari \& Sharma, 2016).

The author proposes this extant literature provides a reasonable framework for discussion about the importance of readiness. Academicians and employers have differences of "opinions" about the career readiness of new graduates from business programs. Corroborating these differences, a survey conducted by the National Association of Colleges and Employers (NACE) states, "results from 4,213 graduating seniors and 201 employing organizations, indicated potential employers did not share the same high ratings as graduating seniors in terms of career readiness" (BizEd AACSB International, 2018, paras. 1-3). It is worth mentioning here that BizEd, is published by the International Association to Advance Collegiate Schools of Business (AACSB International), the accreditation agency for business programs. These findings were further evidenced by a recent discussion by Abston and Soter (2020), who concluded, "While they have acquired the necessary discipline-specific or technical knowledge and skills, many students are sorely lacking when it comes to other skills that are essential to successful careers: collaboration, oral and written communication, interpersonal skills, and professionalism, among others. These career readiness competencies are the most valued by employers according to the 2019 Job Outlook" (p. 266).

The current article seeks to contribute to extant literature about readiness. In the context of this article, readiness is interchangeable with career, job, and workplace; other terms are defined as follow.

Career Readiness is "the attainment and demonstration of requisite competencies that broadly prepare college graduates for a successful transition into the workplace. Competencies include Critical Thinking/Problem Solving, Oral/Written Communications, Teamwork/Collaboration, Digital Technology, Leadership, Professionalism/Work Ethic, Career Management, and Global/Intercultural Fluency" (NACE, 2015).

Employment/employability skills are defined as: basic: functional skills/reading, writing, mathematical; technical: skills sets to complete a specific task, e.g. technological; and, interpersonal/soft skills are defined as employee's ability to get along with others, e.g. communication, listening, teamwork skills (Werner \& DeSimone, 2012).

Skills gap is defined "as a significant gap between an organization's current capabilities and the skills it needs to achieve its goals" (American Society for Training \& Development, 2012, p.4.)

Given the gaps between academicians and industry perceptions about readiness, helping business majors understand the connections between course activities within the scope of expected workplace performance is paramount to professional development and employment prospects. To explore the importance of this connection, the author seeks to extend previous research (see $\mathrm{Yu}, 2010$ ), about learning from workplace assessment. Yu (2010) states, "Professional workplaces, like our classrooms, value longitudinal, contextualized, and collaborative assessment"... (p.36). Yu (2010) states, "By understanding and learning from these methods, business communication teachers can combine the best that classrooms and workplaces have to offer" (p. 36). The author proposes exploring workplace assessment practices to authentically engage business majors, which should improve their contextual insight about industry-expected skills and career readiness resulting in an improvement of their employment prospects. 


\section{Authentic Engagement and Technology}

In the context of pedagogical design, the author seeks to bridge the gaps between theory and practice by describing a simulated workplace project used to help business majors think and reflect on skills gaps, technology use, team building, and future employment. To meet this objective, we analyze challenges potentially linked to technology used in academic settings that may not be as current as technology used in workplace settings. The author draws on experiences in teaching business courses and strategies that promote students' authentic engagement. Following Schlechty's (2002) definition of authentic engagement, "The task, activity, or work the students is assigned or encouraged to undertake is associated with a result or outcome that has clear meaning and relatively immediate value to the student"( p.3). These uncertain times underscore the importance of reflecting on and applying best practices from academic and workplace settings that can authentically engage and develop students with applicable workplace and employability skills.

Typically, when reflecting on pedagogical design, the process may involve perusing related literature (scholarly and industry) to link themes or best practices. Linked in this way, pedagogical options can be identified when examining other resources (e.g. accessing databases of professional organizations or collaborating with other business faculty and business professionals). In so doing, as a business professor, data from tracking comparisons between academic and workplace settings or reviewing discipline-based innovative assignments on professional organizations sites, can yield valuable insight. For example, some literature focusing on differences that might impede team building describe gender, diverse age, cultural, and technological characteristics among academic and workplace team members (Coffelt, Baker \& Corey, 2016; Colvin, 2006; Jones, 2011; Author, 2005). These differences warrant consideration when designing instructional activities to develop team skills (e.g. problem solving, meeting management, writing reports, and delivering presentations). By using these differences and linking them to business practices, business majors might understand the immediate value of academic team preparedness expected for the workplace.

Thus, the author proposes that a relevant course of action is to help business majors gain an understanding by reflecting on and bridging skills gaps due to the digital divide of technology used in the (business) classroom versus the workforce. In workplace settings, team members have frequent access and training on new and innovative technologies with expectations that they will utilize these technologies to improve collaborations (Dittes, Richter, Richter \& Smolnik, 2019; Maruping \& Massimo, 2015). By contrast, in academic settings, team members are more likely to experience limited access to technologies given institutional policies and resources related to purchasing new technology. Larson, Leung and Mullane (2017) provide a comparative review of communication technology tools that provide insight about inherent trade-offs. Relevant to this discussion, findings from the review was helpful when considering how trade-offs stemming from rapid technological changes can cause gaps between the training and development of technological content and skills students receive versus the new and different technological skills expected by industry. Similarly, these trade-offs might also impact critical thinking mentioned in the NACE's survey as having a gap between students' and employers' perceptions (BizEd AACSB International, 2018, para. 2). In academic settings, students are more likely to accept technology tools or procedures as "just the way things are done" to circumvent a difficult conversation. This might potentially impede development of critical thinking strategies. For example, related to this 
article's discussion about technology (Blackboard vs. Google Docs), business majors in the workplace may have budgets that require analyzing issues, collaborating with colleagues, and deciding on technology upgrades. Hence, these findings provide comparative insights and themes useful for designing simulated workplace practices for business courses.

Barneva et al. (2017) describe how pedagogy can be designed to address problems associated with trade-off gaps between technologies and collaborations, which might help students develop skills. A critical element of this pedagogy should include exploring how technological developments are affecting workplace writing and other forms of communication skills necessary for students to successfully enter and maintain employment in the workplace (Bremmer, 2018; Grant, 2018). Taken altogether, findings from studies cited in this article reveal gaps between academic curricula (theory) and industry (practice). These findings provide a basis for questions business faculty can reflect on and use when designing pedagogy linked to business practices. For authentic engagement, the author proposes learning objectives for each section to bring contextual insight with respect to expected "readiness."

\section{Background}

Learning Objective: After classroom study and practice of industry trends, business majors should be able to assess skills gaps and develop strategies to improve workplace readiness.

Drawing from the cited sources above, as well as my pedagogical, research, and consulting practitioner experiences, the discussion is framed with thought-provoking questions to call attention to workable processes and evaluations that might bridge gaps between theory and practice. For example, given the essential role of technology in many workplace settings, team-based interactions may be more accurately labelled social collaboration, or the use of technology to enhance communication and teamwork within an organization (Microsoft, 2013; Shwom \& Snyder, 2016). Extant literature suggests that technology exerts a significant influence on workplace teams. Beyond traditional hardware and software, organizations are increasingly utilizing social media for internal communication and collaboration. Employers with evolving business communication and technological tools underscore the need for business schools to produce graduates with these skill sets (Bremner, 2018; Cardon \& Marshall, 2015; Hartley \& Chatterton, 2015; Jackson, 2012; Mitchell, Skinner \& White, 2010; Moshiri \& Cardon, 2014; Robles, 2012).

By examining and engaging in these workplace practices, academics can explore pedagogically oriented applied research with objective outcomes suitable for addressing the ever-changing business environment. In essence, the classroom becomes a reality-based workplace in which students' readiness and employability can be assessed within industry expectations (Yu, 2010). For this discussion, a simulated workplace project was used in the classroom for business majors to inductively reflect on business communication skill-building activities while developing relevant business competencies. Extending previous research, when issues at the intersection of teamwork and technology are examined from a practitioner's perspective, the literature suggests these challenges may be related to team members' limited understanding of working collaboratively (Author, 2005).

In general, collaboration is defined as the process of working together to achieve a common goal (Shwom \& Snyder, 2016). Academic and workplace teams may hold diverse understandings of the importance of collaboration (i.e., embracing team members' differences in an effort to create an inclusive environment) and simultaneously value collaboration as a means to improving team performance (Sultana, 2014). Yet, gaps in team skills may mean that members adopt strategies that reduce, not enhance, collaboration. For example, academic team members may opt to practice individual skills rather 
than learning new skills based on purposefully exploring and integrating members' differences into teamwork. This is likely to occur when academic team members rely solely on the team leader's schedule versus taking into consideration all team members' schedules when coordinating meetings or written deliverables. While challenging, the latter approach of developing and utilizing coordinating skills is more likely to improve collaboration among team members, but the former approach is often the default.

With this point in mind, changes in the workplace continue to focus more on teams (collaboration) rather than the traditional chain of command. Some organizations operate on the premise that there is a strong correlation between team collaboration and workplace productivity. Further, research demonstrates teamwork increases satisfaction and engagement among employees (Berry, 2011, 2006; Cardon \& Marshall, 2015; Douglas, Martin, \& Krapels, 2006; Lawler \& Finegold, 2000). Thus, team-based collaborative skills have meaningful implications for processes and outcomes and should be practiced (Onrubia \& Engel, 2009). It is reasonable to suggest practicing workplace team collaborations in business courses should also "engage" business majors to be "productive" and develop industry expected team skills.

Academic settings guided by the global Association to Advance Collegiate Schools of Business (AACSB) have defined accreditation standards tasked with responding to workplace changes. Business programs, in particular, must address perceived gaps between industry needs and skill sets of business graduates (AACSB, 2003, 2007, 2011). Thus, revising and/or designing course content inclusive of industry trends in business communication can be a powerful, formal strategy for minimizing deficiencies in skills, such as team collaboration and technology. Additionally, this curricular strategy can have secondary benefits in terms of enhancing undergraduate business majors' perceptions of employability vis-a-vis their skill sets and preparedness for the workforce, an accreditation assessment requirement.

\section{Context and Procedures}

Learning Objective: After classroom study and practice of industry trends, business majors should be able to assess the meaning and value of employability skills in terms of career readiness.

As academicians, we understand how assessment data can be useful when making decisions or adjustments to improve, for instance, learning outcomes, course design to meet business needs, or pedagogical collaborations. Similarly, workplace assessments such as peer review, self-assessment or collaborative assessment, are used to help employees with professional development. Given these related aspects of assessments, helping business majors understand workplace assessment might improve their performance in the classroom and future workplace (Yu, 2010). This is a reasonable suggestion, which may offer meaning and value to both faculty and undergraduate business majors. Business academics often serve as consultants in workplace settings as disciplinary experts and use these experiences to develop reality-based research and pedagogy that enrich classroom experiences. The process and evaluation framework below is shared to help business communication faculty integrate workable pedagogy to ever-evolving business practices.

For instance, business students frequently query faculty concerning use of technological alternatives to existing academic Blackboard Learning Management Systems (LMS). In recent years, students have increasingly asked, "Can we use Google Docs to work on the project rather than Blackboard?" when organizing teams for projects. Based on the author's experience, this question might stem from students' familiarity with Google applications and other web-based tools. Arguably, students seemingly preferred Google Docs, offered within Google Drive, because it allows more collaboration (e.g., sharing and editing documents or presentations) with team members in real time. This anecdotal data 
mirror results of a survey on use of social tools at work (Microsoft, 2013). Findings showed a preference for using social tools, i.e. real time engagement, in the workplace to improve collaborations, teamwork and other work-related activities. Interestingly, the Blackboard LMS has limited interactive tools, yet, remains the preferred platform in higher education (Kim, 2017; Rhode et al, 2017).

This data provides opportunities for revising course design and materials for accreditation assessment and improving learning outcomes to meet business needs. For example, within an accredited College of Business course such as Business Communication, a basic objective for course revisions could be to improve undergraduate business majors' understanding of expected industry skills focusing on social collaboration within the scope of teamwork and technology. Thus, a related project could be to provide undergraduate business majors with opportunities to practice business communication skills such as team building, social collaboration, technological and business writing in a small simulated workplace environment.

The major course assignment, a work-based team learning project, should be designed to emphasize the rationale and skill set for practicing coordination to improve collaboration, i.e. understanding how team members' differences can impact performance. Mindful of authentic engagement, the project should include for theoretical and practical knowledge, assigning reading of specific chapters in the course's textbook and journals within each learners' declared major. Other examples for the project's activities might include mini-assignments requiring assigning roles and tasks, managing conflict, time management, and revising and editing documents (Bremner, Peirson-Smith, Jones, \& Bhatia, 2014). All of these activities can be designed to build a professional portfolio with reflective short themed memorandums, for example skills- team building, social collaboration, technological, detailing how to apply workplace assessments (i.e. peer, self, professor, during the project). Thereby, we enable undergraduate business majors to identify skills gaps, e.g. technology used in the classroom, which might hinder expected workplace performance.

Table 1 provides a sample project outline and grading rubric for the project. The categories and weights for both the outline and rubric can be modified based on the assignments within the project. 
Table 1. Sample Project Outline and Rubric

\begin{tabular}{llc}
\hline Activities & Deliverable & \% of Grade \\
Objective of the assignment & Discussion Q\&A & \\
Reading materials/course \& journals & Authenticity Engagement & $10 \%$ \\
Team Selection & Small Company/Name & \\
Teams/Goals \& Expected Outcomes & Memorandum & $10 \%$ \\
Research/Skill Development & Team Report & $30 \%$
\end{tabular}

\section{Elements}

Assignment Content and

Organization

Applied Directions

Work plan and assignment

Informative and persuasive

Visual Communication

Industry Readiness

Layout

Use of visual aids/applicable and effective

Easy to Navigation/links and appendix

Word Choice/Tone

Key terms defined

Words are precise and well-chosen

Words are appropriate to the subject matter

Mechanics

Effective proofreading

Consistency/ logically sound/facts cited are relevant

Any agreement errors

Format

Correct documentation style (quotes/sources)

Clear logical sentences

Clear logical paragraphs

Total Points

Summary Feedback 
Adapted from Kryder 2003 and McCarthy \& McCarthy 2003

Both the outline and rubric were originally adapted from Business Communication colleagues: Focus on Teaching/Grading for Speed, Consistency and Accuracy (Kryder, 2003) and My Favorite Assignment/ Redesigning the Work in Business Communication (McCarthy \& McCarthy, 2003). The original adaptions were driven by discussions at professional conferences with the listed authors, as well as by this author's desire to help undergraduate business majors develop writing skills and desire for consistency in the grading process/feedback during similar projects. The author then used direct student feedback, collaborations ( e.g. business communication faculty at professional conferences, workplace professionals and consulting experiences), and a semester-by-semester debriefing process to refine project materials and rubrics via multiple iterations of the Business Communication course over several years. Thus, the author can attest that the major project assignment maintains good rigor, quality for achieving course objectives, and relevance in response to meeting business needs. The outline and rubric are solid assessment tools that can be modified to evaluate student performance on key elements of assignments. The following suggestions provide guidance for authentic reflections on how to design the project.

\section{The Project and Activities}

The required course Business Communication provides an ideal simulated workplace setting. Students enrolled are normally upper level undergraduate business majors across disciplines (e.g. accounting, general business, management, management information systems, marketing, and supply chain). Demographics reflect the diversity found within many workplace settings: age, gender, major, ethnicity, various skill set levels, and work experience. Classes mirroring this setting provide contextual relevance when explaining the course and project objectives to students at the beginning of the semester, specifically when discussing the course objective that assignments/projects in the classroom are designed to equip undergraduate business majors with industry-expected skills. When students receive this type of orientation, it might provide a "reality check" and can prompt linking content to business practices beyond just earning a grade.

To authenticate this point and make it memorable, engage students with a project activity. For example, randomly assign teams or ask students their preference, remind students that these teams will not change during the semester and form teams to reflect the diversity (i.e. mixed majors, genders, experiences, etc.) found within many workplace settings. This should generate a lively discussion, even more so, when prompting collaboration by asking the whole class to decide the name of the class/company before working collaboratively with their team members on the project. Of course, modifications can be made to this setup given a number of factors such as number of students enrolled in the class, course mode, meeting time, and regional or specific business practices.

In terms of business practices, as part of the project, team members can be tasked with challenging assignments that no one member could complete individually. For instance, ask members to discuss a question about managing team conflict focusing on generational preferred technology. A number of open-ended questions (accountability, similarities, and differences) can be added to create robust team conversations. After discussion, mini-writing assignments, team and individual, can be used to detail initial team communication protocol. For example, students could write memorandums, both team (outline topics to include in the team's contract) and individual (peer review of team members' 
performance). This activity is twofold: members should be able to identify technological skills gaps among team members as well as practice soft skills, including effective communication, managing conflict, and critical thinking.

In the team project above, to create a professional portfolio, several mini-writing assignments could be used to capture experiences related to team collaboration via Google Docs and Blackboard LMS (e.g., memorandum with team goals and expected outcomes or blogs about ethical use of social media in the class/company). Another example, for prompting authentic engagement is using workplace presentations such as random selection of teams or members to provide weekly project updates. This should help with time management if the project is phased over the semester. For instance, the project might include two phases: four weeks using Google Docs and four weeks using Blackboard. Each team would develop and submit a final report on the nature and quality of their team's acquisition and utilization of industry-expected collaboration skills using technology over the two project phases. Each team member would also complete a self-assessment reporting, reflective paper and/or team review, on their acquisition of industry-expected collaboration skills for undergraduate business majors, ability to apply technology within their teams, and readiness for careers in industry.

\section{Discussion and Recommendations}

Learning Objective: After classroom study and practice of industry trends, business majors should be authentically engaged about future employment prospects.

For course revisions, this project will generate information to glean insight about undergraduate business majors' perceived gaps linked to team skills and technology, as well as, preferred technology such as Google Docs both before (pre) and after (post) the project. In general, this might show a linkage to social collaboration options with team members in real time, i.e. enhanced collaboration-simultaneous editing, messaging, and other features. This information provides a basis for reflecting and revising the course project. Implications from this project are made based on the author's experiences and reflective research. Some themes to peruse in literature and other resources include Team Skills and Social Collaboration and Business Communication Skills--Academic and Industry Expectations. Based on using the simulated workplace performance, over the years, it is feasible for the author to propose undergraduate business majors' have been authentically engaged and gained meaning and value from participating in this collaborative and technology skills development project. For research purposes, the project has the ability to extend literature on theory into practice in terms of business communication, pedagogy, and technology preference. However, there are limitations related to technology and industry participation. While Google Docs is widely disseminated and accessible, industry, particularly those organizations known for technological innovation, may be early adopters of newer technologies. In contrast, academia, known for intellectual but not necessarily technological innovations, may greatly lag in adopting newer technology. In this project, the author/instructor chose to use Google Docs rather than a new version of technology. By doing so, the project supports the need for improving institutional access to technology in an effort to maximize undergraduate business majors' acquisition of skills expected for career success. It is important to recognize and respond to accreditation and industry expectations in business courses such as Business Communication that help business majors understand the impact of technology on business writing. This limitation underpins a second limitation that focuses on a need for industry input to business college curricula in terms of defining specific technology skills. Academicindustry collaboration can help reduce academic and industry team members' perceptions of skills gaps related to technology. Such collaborations can also support development of specific skills, in this case for undergraduate business majors, for emerging technologies rather than a generalized list of technical skills. 
As mentioned earlier, this project might reveal that undergraduate business majors prefer Google Docs for coursework rather than the Blackboard LMS. However, it is worth mentioning or expressing concerns in terms of the rapid pace of innovative technology including Blackboard LMS. In reflecting on my summative experiences, a consistent thread of conversation focused on academic settings' inability to "keep up" with the fast-paced and different technology used by industry. This represents a "valid" concern because it also means changing technology will require rapid changes in academic settings to equip, in general all students, with industry expected skills. It seems reasonable to continue recommending business communication faculty collaborate with industry representatives to identify technologies and other skills to minimize perceived gaps between theory and practice. This collaboration might also provide opportunities for faculty and students to develop, understand, and practice emerging technologies that can improve course content and activities.

Developing challenging coursework that allows undergraduate business majors to learn and practice industry expected skills (e.g., team-based skills, social collaboration, technology, and collaborative writing in real-time) also allows students to "cross talk" between academic and industry mentors and colleagues. As suggested by the author, it may be a feasible, "best practice" in business courses to simultaneously use both an academic system, Blackboard LMS, and other technology such as Google Docs, especially, given the workplace-based pedagogical implications for both, a diverse pool of undergraduate business majors and their Business Communication professor. The key takeaway points to a need for incorporating more course exercises and coverage of team skills and use of various technologies in Business Communication courses. For example, one area for future discussion involves how business majors/field of study affects technological preferences (Blackboard LMS or Google Docs) with respect to development of team-based skills, social collaboration, and business communication skills.

Another notable area worthy of future discussion and practice is learning how to develop and utilize individual skills via team-based collaboration given team members' diversity and differences. Drawing from this project, a starting point might involve expanding the report on industry-expected skills related to undergraduate business majors to an inventory of team members' skills. Then, identify and write curricular modules for academic curricula, such as a short training blog about how to train team members with a new skill, for example using Google Docs. Other team-based skills worthy of consideration include those necessary to utilize computer conferencing technologies to communicate, collaborate, and connect with individuals and teams to complete required course assignments and/or projects. These training tools should incorporate "best practices" learned from academic-industry partnerships and be integrated into Business Communication courses. Doing so can prepare business majors with team and technological skills that are current and meet the needs of industry.

\section{Conclusion}

Discussion about this simulated workplace project contribute to the literature about bridging skills gaps between theory and practice. Business programs need to examine industry trends that influence methods to equip undergraduate business majors with applicable 21st century workplace skills. Information from this project will also contribute to assessment data in terms of pedagogical strategies linked to collaborative and reality-based learning. This information is relevant to developing and implementing "innovative" business programs and course content. The process and evaluation framework allows for modifications by business communication faculty and others teaching in a variety of settings. To this end, for AACSB accreditation purposes, artifacts from the project can be collected and qualitatively 
analyzed focusing on what can be learned and applied from this project as business faculty and employers to improve business programs.

Although these suggestions will not pertain equally to all business communication settings (i.e. regional or local practices), they do allow for the examination, reflection, and application of best practices to bridging the gaps between theory and practice in terms of providing meaning and value for undergraduate business majors to develop applicable workplace and employability skills. To illustrate this point, the author shares narratives about pedagogy, research, and consulting practitioner experiences with business majors to authenticate the importance of developing and keeping my teaching relevant in order to have a positive impact on students' (business majors) and graduates' (business professionals) "readiness." These discussions allow the author to explicitly share how pedagogy described in this article has reciprocal benefits for both students and professors in terms of "authentic engagement of classroom and workplace "readiness." Currently, academic and workplace settings are navigating a challenging time in which there is a need to adapt and learn meaningful and valuable reality-based transferable skill sets.

It is anticipated that this article will contribute to extend literature related to themes focusing on authentic engagement, business communication, readiness, theory and practice. This discussion should also help support proposals that address the digital divide in terms of equipping academic settings with quality technology and computers. Such discussions may help academicians and employers find common ground, especially given the well-documented need for technology tools and software with respect to our evolving business practices. It is necessary to emphasize that academia and industry must bridge the gap between theory and practice. 


\section{References}

AACSB International - The Association to Advance Collegiate Schools of Business. (2003). Proposed eligibility procedures and standards for business accreditation. Retrieved from http://www.aacsb.edu/conferences/events/seminars.asp

AACSB International - The Association to Advance Collegiate Schools of Business. (2007). Eligibility procedures and accreditation standards for business. Tampa, FLA. AACSB International.

AACSB International - The Association to Advance Collegiate Schools of Business. (2011). Recommendations to AACSB International from the globalization of management education task force. 3, Tampa, FLA. AACSB International.

Abston, K. \& Soter, H. ( 2020). A Professionalism Conundrum: Development of Business Students' Career Readiness. Developments in Business Simulation and Experiential Learning, 47, 266- 271.

American Society for Training \& Development. (2012). Bridging the skills gap. Alexandria, VA.

Barneva, R. P., Gelsomini, F., Kanev, K., \& Bottoni, P. (2017). Tangible technology-Enhanced learning for improvement of student collaboration. Journal of Educational Technology, 46, 284-302.

Berry, G. R. (2006). Can computer-mediated asynchronous communication improve team processes and decision making? Learning from the management literature. Journal of Business Communication, 43 (4), 344-366.

Berry, G. R. (2011). Enhancing effectiveness on virtual teams: Understanding why traditional team skills are insufficient. Journal of Business Communication, 48 (2), 186-206.

BizEd. (2018). Are New Grads Ready for Work? Retrieved from https://www.bized.aacsb.edu/articles/2018/05/are-new-grads-ready-for-work

Bremner, S., Peirson-Smith, A., Jones, R., \& Bhatia, V. (2014). Task design and interaction in collaborative writing: The student's story. Business Communication Quarterly, 77, 150-168.

Bremner, S. (2018). Workplace writing: Beyond the text. New York, NY: Routledge.

Cardon, P. \& Marshall, B. (2015). The hype and reality of social media use for work collaboration and team communication. International Journal of Business Communication, 52, 273-293.

Coffelt, T. A., Baker, M. J., \& Corey, R. C. (2016). Business communication practices from employers' perspectives. Business and Professional Communication Quarterly, 79, 300-316.

Colvin, G. (2006). Why dream teams fail. Fortune, 87-92.

Dittes, S., Richter, S., Richter, A., \& Smolnik, S. (2019). Toward the workplace of the future: How organizations can facilitate digital work. Business Horizons, 62, 649-661.

Douglas, C., Martin, J. S., \& Krapels, R. H. (2006). Communication in the transition to self directed teams. Journal of Business Communication, 43 (4), 295-321.

Dragoo, A. \& Barrows, R. (2016). Implementing Competency-Based Business Curricula in Higher Education. Journal of Education for Business, 91 (6), 1-6. 
Grant, L. (2018). [Review of the Book Workplace writing: Beyond the text by S. Bremmer]. Business and Professional Communication Quarterly, 8 (4), 506-512.

Hartley, P. \& Chatterton, P. (2015). Business communication. Rethinking your professional practice for the post-digital age (2nd ed.) New York, NY: Routledge.

Jackson, D. (2012). Business Undergraduates' Perceptions of Their Capabilities in Employability Skills: Implications for Industry and Higher Education. Industry \& Higher Education, 26 (5), 345-356.

Jones, C. (2011). Written and Computer -Mediated Accounting Communication Skills: An Employer Perspective. Business Communication Quarterly, 74 (3), 247-271.

Kim, J. (2017). How Big is the LMS Market? Inside Higher Education, Technology \& Learning. Retrieved from https://www.insidehighered.com/blogs/technology-and-learning/how-big-Ims-market

Kryder, L. (2003). Grading for Speed, Consistency and Accuracy. Business Communication Quarterly, 66 (1), 90-96.

Larson, B., Leung, O., \& Mullane, K. (2017). Tools for teaching virtual teams: A comparative resource review. Management Teaching Review, 2, 333-347.

Lawler, E. \& Finegold, D. (2000). Individualizing the organization: Past, present, and future. Organizational Dynamics, 29, 1-15.

MacDermott, C. \& Ortiz, L. (2017). Beyond the Business Communication Course: A Historical Perspective of the Where, Why, and How of Soft Skills Development and Job Readiness for Business Graduates. The IUP Journal of Soft Skills, XI (2), 1-18.

Maruping, L. \& Magni, M. (2015). Motivating employees to explore collaboration technology in team contexts. MIS Quarterly, 39, 1-16.

McCarthy, P. \& McCarthy, H. (2003) Redesigning the Work in Business Communication. Business Communication Quarterly, 66 (4), 65-71.

McNamara, B. (2009). The skill gap: Will the future workplace become an abyss. Techniques: Connecting Education and Careers, 84 (5), 24-27. Retrieved from ERIC database. (EJ840446)

Microsoft. (2013). Bring your own service: Employees want social tools at work, despite company restrictions and hesitations, reports new Microsoft survey. Retrieved from https://news.microsoft.com/2013/05/28/bring-your-own-service-employees-want-social-tools at-work-despite-company-restrictions-and-hesitation-reports-new-microsoft-survey/

Mitchell, G., Skinner, L. \& White, B. (2010). Essential soft skills for success in the twenty-first century workforce as perceived by business educators. Delta Pi Epsilon Journal, 52, 43-53.

Moshiri, F. \& Cardon, P. (2014). The State of Business Communication Classes: A National Survey, Business and Professional Communication Quarterly, 77, 312-329.

Author (2005). Integrating Soft Skills through Active Learning In The Management Classroom. Journal of College Teaching and Learning, 2 (4), 1-6.

NACE -National Association of Colleges and Employers. (2015). Career Readiness Defined. Retrieved from https://www.naceweb.org/career-readiness/competencies/career-readiness-defined/ 
Onrubia, J. \& Engel, A. (2009). Strategies for collaborative writing and phases of knowledge construction in CSCL environments. Computers \& Education, 53, 1256-1265.

Peddle, M. (2000). Frustration at the Factory: Employer Perceptions of Workforce Deficiencies and Training Trends. Journal of Regional Analysis and Policy, 30 (1), 23-40.

Rhode, J., Richter, S., Gowen, P., Miller, T., \& Wills, C. (2017). Understanding faculty use of the learning management system. Online Learning, 21 (3), 68-86.

Robles, M. (2012). Executive Perceptions of the Top 10 Soft Skills Needed in Today's Workplace. Business Communication Quarterly, 75 (4), 453-465.

Schlechty, P. (2002). Working on the work. San Francisco: Jossey-Bass.

Shwom, B. \& Snyder, L. (2016). Business Communication: Polishing Your Professional Presence. (3rd ed.) Pearson.

Sultana, N. (2014). Soft skills for employability. International Journal of Organizational Behavior \& Management Perspectives, 3 (1), 745-749.

Tewari, R. \& Sharma, E. (2016). An Investigation into the Expectations of the Recruiters and the Preparedness of the Management Graduates for Effective On-Job Performance. The IUP Journal of Soft Skills, 10 (1), 14-23.

Thomas, G. (2007). How Can We Make Our Research More Relevant? Bridging the Gap Between Workplace Changes and Business Communication Research. Journal of Business Communication, 44 (3), 283-296.

Werner, J. \& DeSimone, R. (2012). Human resource development. Mason, OH: South-Western.

$\mathrm{Yu}, \mathrm{H}$. (2010). Bring workplace assessment into business communication classrooms: A proposal to better prepare student for professional workplaces. Business Communication Quarterly, 73 (1), 21-39. 


\section{About the Author}

Chynette Nealy (nealyc@uhd.edu) is a professor of business administration at the University of Houston Downtown. In her work, she is directly concerned with teaching and researching skills that can be applied to bridging the gap between theory and practice. Address correspondence to Chynette Nealy, Department of General Business, Marketing and Supply Chain, Marilyn Davies College of Business, University of Houston Downtown, 320 North Main, Suite B420, Houston, Texas 77002; email: nealyc@uhd.edu 